\title{
Dynamic Analysis on Nonlinear Fluid-Structure Interaction Forces of Rub-Impact Rotor System
}

\author{
Yuegang Luo*, Songhe Zhang, Bin Wu and Wanlei Wang \\ College of Electromechanical \& Information Engineering, Dalian Nationalities University, Dalian, 116600, China
}

\begin{abstract}
Based on the coupling model of nonlinear oil-film force and nonlinear seal fluid force, a nonlinear dynamic model of rotor system with rub-impact fault is set up. The dynamic characteristics of the system were studied with numerical simulation and the effects of airflow excited force, rubbing gap and stiffness parameters on movement characteristics of the rotor were analyzed. The results indicate that the airflow excited force can significantly restrain the stability and amplitude of rubbing rotor. The less rubbing gap and larger rubbing stiffness are in favor of the stability of the system.
\end{abstract}

Keywords: Airflow excited force, bifurcation, nonlinear fluid-structure interaction, rotor system, rub-impact.

\section{INTRODUCTION}

Rub-impact is the important and typical fault of rotor system. The main reasons leading to rub-impact fault between the rotor and stator are unbalance, assembling error, misalignment, stator casing motions, pedestal looseness, bearing gap being improper, and so on. Based on the needs of the dynamics design and fault diagnosis, the problems of rub-impact fault gathered the attention of engineering academic circles. Ehrich [1] has conducted researches about bifurcation and chaotic responses caused by the rub-impact fault of the rotor system. Chu et al. [2, 3] studied the complicated dynamics behavior of the Jeffcott rotor with rub-impact adopting piecewise linear rub-impact force based on short-bearing mechanics model. It is indicated that the system shows different forms of periodic motions and quasiperiodic motions, chaotic motions and bifurcation phenomena. Sun et al. [4] analyzed the mathematical model of the rotor with clearance by applying modern nonlinear dynamics theory. The results indicated in the bifurcation diagrams of the change of rotating speed, that in the supercritical wheeling speed, the motions of the system alternates between periodic vibration and chaos, and the period of vibration will add one after another a region of chaos. In the same time, the number of the periods is equal to the whole number multiples of critical wheeling speeds. Wang et al. [5] developed a differential equation expressing the motion of a rotor system with slow-varying mass. The effects of changes in rotor speed and unbalance on the vibration of a rubbed/impacted rotor system were analyzed through numerical method. The results indicate that the rubbed/impacted rotor system with slow-varying mass is equivalent to a rotor system with time-dependent damping and stiffness, which has obvious quasi-periodical motion features in its rubbed/impacted process, but there are no

*Address correspondence to this author at the College of Electromechanical \& Information Engineering, Dalian Nationalities University, No. 18 Liaohe west Road, Dalian, Postcard: 116600, China; Tel: 86-411-87182084;

E-mail: luoyg@dlnu.edu.cn chaotic motions arising from the constant mass of rotor system.

There are nonlinear fluid-structure interactive forces of the rotor system, such as nonlinear oil-film force, airflow excited force, which have significant influence on the dynamic characteristics of the system. So it is necessary to study the influence of the nonlinear fluid-structure interaction forces on the rubbing rotor system. Ren et al. [6] built the mechanical and numerical model of a dualdiscover-hung rotor-bearing system respectively. The influences of nonlinear characteristics of rotor system with rubbing fault on eccentricity, clearance, and rubbing on middisc were analyzed by using the experimental instrument for rubbing fault. And the rotor systems with rubbing on middisc and rubbing on over-hung disc were also studied. Luo et al. [7] established the dynamic model of the two-span rotorbearing system with rub-impact faults, the nonlinear dynamics behaviors induced by rub-impact faults of one disk or two discs were numerically studied. The results show that there are two self-existent islands in the regions of chaotic motion when rub-impact of two discs happens. The response becomes more instable along with the increase of eccentricity. Li et al. [8] analyzed the nonlinear dynamic behaviors of a rotor-bearing system with rub-impact on a continuous model, adopting the finite element method (FEM) in the analysis for rub-impact behaviors. And the bifurcation and chaos behaviors of the rub-impact phenomenon were analyzed by the Newmark- $\beta$ method. The results indicate that there is abundant nonlinear phenomenon of the rotor-bearing system with rub-impact with the changing of different factors, and the airflow excited force imposed on the rotor will significantly increase along with the structural parameter enhancement of rotary machinery. Pertaining to the rotor-case-sealed rubbing system, Yin et al. [9] established a coupled dynamical equation using the Muszynska nonlinear sealed force model. Based on physical and structural parameters of labyrinth sealing, the motional properties of rubbing rotor are numerically analyzed. And the results show that the system possesses various nonlinear 
dynamical inherences. The major sealed structural parameters greatly affect the system stability, whereas the dynamic stability can be improved through adjusting sealing parameters. Yuan et al. [10] studied dynamic characteristics of rotor's axial rub-impact with the consideration of turborotor's nonlinear fluid-structure interaction forces in six degree-of-freedoms of the rotor, and the dynamic behaviors of the system were analyzed. The influences of the nonlinear clearance-excitation fluid force of turbo-rotor on the dynamic behaviors of rotor's axial rub-impact are insignificant. The only effects are the appearances, in the axial response, of the higher order super-harmonic components of even-time working frequency at low rotating speeds. Zhang et al. [11] set up a dynamic model of the three-span rotor-bearing system with rub-impact fault. And the influence of nonlinear dynamics behaviors of the rotorbearing system induced by rub-impact of one disc, two discs and three discs, were numerically studied. The results indicate that in the supercritical rotate speed, the influences of the rotor system response by the rub-impact faults are significant. There are mutations of amplitudes in the responses of second and third spans in supercritical rotating speed when there is rub-impact with one disc, and there are chaotic windows in the response of first span, and jumping changes in second and third spans when there are rubimpacts with two or three discs. In this paper, the dynamic vibration characteristics of the rotor-bearing-seal system with rub-impact fault were analyzed by the numerical integrated method, and the effects of airflow excited force, rubbing gap and stiffness on movement character of the rotor were investigated.

\section{MODEL OF THE RUB-IMPACT ROTOR AND MOTION DIFFERENTIAL EQUATIONS}

Fig. (1) is the model of the rotor-bearing-seal system and rub-impact force. Shaft coupling connects the motor and rotor. The system mass is equivalently concentrated on the center of every disc and bearing support. The torsional vibration and gyro moment are neglected and only the lateral vibration of system is considered. Both ends of the rotor are supported by journal bearings with symmetrical structures. $\mathrm{O}_{1}$ is geometric centers of bearing, $\mathrm{O}_{2}$ is geometric centers of rotor, $\mathrm{O}_{3}$ is center of mass of rotor, $m_{1}$ is lumped masses of rotor at bearing, $m_{2}$ is equivalently lumped masses at disc. The shaft with zero quality connects disc with bearing, $k$ is the stiffness of elastic shaft, and $k_{\mathrm{c}}$ is the stiffness coefficient of the stator. $F_{x}$ and $F_{y}$ are nonlinear oil film forces, and $P_{x}$ and $P_{y}$ are nonlinear seal fluid forces.

\subsection{Oil-Film Force of Short Bearing}

Non-dimensional Reynolds equation based on oil-film of short bearing assumption is expressed as:

$\left[\frac{R}{L}\right]^{2} \frac{\partial}{\partial z}\left(h^{3} \frac{\partial p}{\partial z}\right)=x \sin \theta-y \cos \theta-2\left(x^{\prime} \cos \theta+y^{\prime} \sin \theta\right)$

where $R$ is the radius of bearing, $L$ is the length of bearing. Non-dimensional nonlinear oil-film force can be obtained from the above formula as:

$$
p=\frac{1}{2}\left[\frac{L}{D}\right]^{2} \frac{\left(x-2 y^{\prime}\right) \sin \theta-\left(y+2 x^{\prime}\right) \cos \theta}{(1-x \cos \theta-y \sin \theta)^{3}}\left(4 z^{2}-1\right)
$$

Non-dimensional nonlinear oil-film force can be finally expressed as:

$$
\begin{aligned}
& \left\{\begin{array}{l}
f_{x} \\
f_{y}
\end{array}\right\}=-\frac{\left[\left(x-2 y^{\prime}\right)^{2}+\left(y+2 x^{\prime}\right)^{2}\right]^{1 / 2}}{1-x^{2}-y^{2}} . \\
& \left\{\begin{array}{l}
3 x V(x, y, \alpha)-\sin \alpha G(x, y, \alpha)-2 \cos \alpha S(x, y, \alpha) \\
3 y V(x, y, \alpha)+\cos \alpha G(x, y, \alpha)-2 \sin \alpha S(x, y, \alpha)
\end{array}\right\}
\end{aligned}
$$

where

$$
\begin{aligned}
& V(x, y, \alpha)=\frac{2+(y \cos \alpha-x \sin \alpha) G(x, y, \alpha)}{1-x^{2}-y^{2}} \\
& S(x, y, \alpha)=\frac{x \cos \alpha+y \sin \alpha}{1-(x \cos \alpha+y \sin \alpha)^{2}} \\
& G(x, y, \alpha)=\frac{2}{\left(1-x^{2}-y^{2}\right)^{1 / 2}}\left[\frac{\pi}{2}+\operatorname{arctg} \frac{y \cos \alpha-x \sin \alpha}{\left.\left(1-x^{2}-y^{2}\right)^{1 / 2}\right]}\right. \\
& \alpha=\operatorname{arctg} \frac{y+2 x^{\prime}}{x-2 y^{\prime}}-\frac{\pi}{2} \operatorname{sign}^{1 / 2}\left[\frac{y+2 x^{\prime}}{x-2 y^{\prime}}\right]-\frac{\pi}{2} \operatorname{sign}\left(y+2 x^{\prime}\right)
\end{aligned}
$$

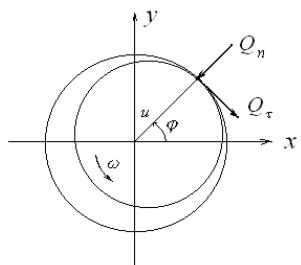

Fig. (1). Models of rotor-bearing-seal coupling system and rubimpact force.

\subsection{Nonlinear Seal Fluid Force (Airflow Excited Force)}

The Muszynska's model is applied to investigate the nonlinear behaviors of seal fluid force, which can be expressed as [12]:

$$
\begin{aligned}
& \left\{\begin{array}{l}
P_{x} \\
P_{y}
\end{array}\right\}=-\left[\begin{array}{cc}
K-m_{f} \tau_{f}^{2} \omega^{2} & \tau_{f} \omega D \\
-\tau_{f} \omega D & K-m_{f} \tau_{f}^{2} \omega^{2}
\end{array}\right]\left\{\begin{array}{l}
x \\
y
\end{array}\right\} \\
& -\left[\begin{array}{cc}
D & 2 m_{f} \tau_{f} \omega \\
-2 m_{f} \tau_{f} \omega & D
\end{array}\right]\left\{\begin{array}{l}
\dot{x} \\
\dot{y}
\end{array}\right\}-\left[\begin{array}{cc}
m_{f} & 0 \\
0 & m_{f}
\end{array}\right]\left\{\begin{array}{l}
\ddot{x} \\
\ddot{y}
\end{array}\right\}
\end{aligned}
$$

where, $\omega$ is the rotational angular velocity, $K, D$ and $m_{f}$ respectively represent equivalent stiffness, equivalent damping and equivalent mass. $\tau_{f}$ is the average velocity ratio of fluids. $K, D$ and $\tau_{f}$ are the nonlinear functions of the displacements $x$ and $y$, which can be expressed as:

$$
\left\{\begin{array}{l}
K=K_{0}\left(1-e^{2}\right)^{-n} \\
D=D_{0}\left(1-e^{2}\right)^{-n}, \quad n=0.5 \sim 3 \\
\tau_{f}=\tau_{0}(1-e)^{b}, \quad 0<b<1
\end{array}\right.
$$

where $e=\sqrt{x^{2}+y^{2}} / c_{s}$ is the relative eccentricity of rotor, $c_{s}$ is the seal gap, $n, b$ and $\tau_{0}$ are the seal parameters, general $\tau_{0}<0.5 . K_{0}, D_{0}$ and $m_{f}$ can be calculated by BlackChilds formulas [13]. 
$K_{0}=\mu_{3} \cdot \mu_{0}, \quad D_{0}=\mu_{1} \mu_{3} T, \quad m_{f}=\mu_{2} \mu_{3} T^{2}$

$$
\left\{\begin{array}{l}
\mu_{0}=\frac{2 \sigma^{2}}{1+z+2 \sigma} E\left(1-m_{0}\right) \\
\mu_{1}=\frac{2 \sigma^{2}}{1+z+2 \sigma}\left[\frac{E}{\sigma}+\frac{B}{2}\left(\frac{1}{6}+E\right)\right] \\
\mu_{2}=\frac{\sigma\left(\frac{1}{6}+E\right)}{1+z+2 \sigma} \\
\mu_{3}=\frac{\pi R \Delta P}{\lambda} \\
T=\frac{l}{v_{a}} \\
\lambda=n_{0} R_{a}^{m_{0}}\left[1+\left(\frac{R_{v}}{R_{a}}\right)^{2}\right]^{\frac{1+m_{0}}{2}} \\
\sigma=\frac{\lambda l}{c_{s}} \\
E=\frac{1+z}{1+z+2 \sigma} \\
B=2-\frac{\left(\frac{R_{v}}{R_{a}}\right)^{2}-m_{0}}{\left(\frac{R_{v}}{R_{a}}\right)^{2}+1} \\
R_{v}=\frac{R c_{s} \omega}{\gamma} \\
R_{a}=\frac{2 v_{a} c_{s}}{\gamma}
\end{array}\right.
$$

\subsection{Rub-Impact Force}

It is assumed that there is an initial clearance of $\delta_{0}$ between the rotor and stator, when rub-impact fault occurs, the radial impact force and the tangential rub force can be expressed as:

$$
\left\{\begin{array}{l}
Q_{n}=\left(e-\delta_{0}\right) k_{c} \\
Q_{\tau}=(f+b v) Q_{n}
\end{array} \quad\left(e \geq \delta_{0}\right)\right.
$$

where $f$ is the friction coefficient without regard to velocity influence, $v=\sqrt{\dot{x}^{2}+\dot{y}^{2}}$ is relative slip velocity between rotor and stator. When rub-impact happens, the radial impact force and the tangential rub force can be written in $x-y$ coordinate as:

$$
\left\{\begin{array}{l}
Q_{x} \\
Q_{y}
\end{array}\right\}=-\frac{\left(e-\delta_{0}\right) k_{c}}{e}\left[\begin{array}{cc}
1 & -(f+b v) \\
(f+b v) & 1
\end{array}\right]\left\{\begin{array}{l}
x \\
y
\end{array}\right\} \quad\left(e \geq \delta_{0}\right)
$$

\subsection{Motion Differential Equations}

The radial displacements of axes center of rotor system in left are assumed as $\left(x_{1}, y_{1}\right)$ respectively, the radial displacements of disc are $\left(x_{2}, y_{2}\right)$ respectively, then non- dimensional motion differential equations of system can be expressed as:

$$
\left\{\begin{array}{l}
\ddot{x}_{1}+\xi_{1} \dot{x}_{1}+\eta_{11} x_{1}-\eta_{12} x_{2}=\frac{1}{M_{1}} f_{x}\left(x_{1}, y_{1}, \dot{x}_{1}, \dot{y}_{1}\right) \\
\ddot{y}_{1}+\xi_{1} \dot{y}_{1}+\eta_{11} y_{1}-\eta_{12} y_{2}=\frac{1}{M_{1}} f_{y}\left(x_{1}, y_{1}, \dot{x}_{1}, \dot{y}_{1}\right)-G_{1} \\
\ddot{x}_{2}+\xi_{2} \dot{x}_{2}+2 \eta_{22} x_{2}-2 \eta_{21} x_{1}=\frac{\bar{P}_{x}+Q_{x}}{N}+\frac{1}{M_{2}} \cos \tau \\
\ddot{y}_{2}+\xi_{2} \dot{y}_{2}+2 \eta_{22} y_{2}-2 \eta_{21} y_{1}=\frac{\bar{P}_{y}+Q_{y}}{N}+\frac{1}{M_{2}} \sin \tau-G_{2}
\end{array}\right.
$$

where, $\quad \xi_{1}=\frac{c_{1}}{m_{1} \omega}, \quad \xi_{2}=\frac{c_{2}}{\left(m_{2}+m_{f}\right) \omega}, \quad c_{1}$ is damping coefficient of bearing; $c_{2}$ is damping coefficient of disc, $\eta_{11}=\frac{k}{m_{1} \omega^{2}}, \eta_{12}=\frac{k c_{s}}{m_{1} c \omega^{2}}, \eta_{21}=\frac{k c}{\left(m_{2}+m_{f}\right) c_{s} \omega^{2}}$, $\eta_{22}=\frac{k}{\left(m_{2}+m_{f}\right) \omega^{2}}$.

The parameter $c$ is the bearing gap.

$M_{1}=\frac{m_{1} c \omega^{2}}{\delta_{1}}, M_{2}=\frac{\left(m_{2}+m_{f}\right) c_{s}}{m_{2} e}, N=\left(m_{2}+m_{f}\right) \omega^{2}$,

$G_{1}=\frac{g}{c \omega^{2}}, G_{2}=\frac{m_{2} g}{\left(m_{2}+m_{f}\right) c_{s} \omega^{2}}, x_{1}=\frac{X_{1}}{c}, y_{1}=\frac{Y_{1}}{c}$,

$x_{2}=\frac{X_{2}}{c_{s}}, y_{2}=\frac{Y_{2}}{c_{s}}$.

$\tau$ is non-dimensional time,

$\tau=\omega t . f_{x}=\frac{F_{x}}{\delta}, f_{y}=\frac{F_{y}}{\delta}$ are non-dimensional nonlinear oil-film force components, which are shown in the formula (3). $\delta$ is Sommerfeld correction coefficient, $\delta=\frac{\mu \omega R L}{m_{i} g}\left(\frac{R}{c}\right)^{2}\left(\frac{L}{2 R}\right)^{2}, \mu$ is viscidity of lubricant. $Q_{x}$ and $Q_{y}$ are the rub-impact forces, as are in the formula (14). $\bar{P}_{x}$ and $\bar{P}_{y}$ are non-dimensional nonlinear seal fluid forces.

$$
\begin{aligned}
\left\{\begin{array}{l}
\bar{P}_{x} \\
\bar{P}_{y}
\end{array}\right\}= & -\left[\begin{array}{cc}
K-m_{f} \tau_{f}^{2} \omega^{2} & \tau_{f} \omega D \\
-\tau_{f} \omega D & K-m_{f} \tau_{f}^{2} \omega^{2}
\end{array}\right]\left\{\begin{array}{l}
x \\
y
\end{array}\right\} \\
& -\omega\left[\begin{array}{cc}
D & 2 m_{f} \tau_{f} \omega \\
-2 m_{f} \tau_{f} \omega & D
\end{array}\right]\left\{\begin{array}{l}
\dot{x} \\
\dot{y}
\end{array}\right\}
\end{aligned}
$$

\section{NUMERICAL CALCULATION RESULTS ANALYSIS}

\subsection{Analysis of Influence of Nonlinear Seal Fluid Force}

The parameters of the system are: $m_{1}=4.0 \mathrm{~kg}, m_{2}=32.1 \mathrm{~kg}$, $R=25 \mathrm{~mm}, L=12 \mathrm{~mm}, c=0.12 \mathrm{~mm}, c_{\mathrm{s}}=0.5 \mathrm{~mm}, \mu=0.018 \mathrm{P}_{\mathrm{a}} \cdot \mathrm{s}$, $c_{1}=1050 \mathrm{~N} \cdot \mathrm{s} / \mathrm{m}, \quad c_{2}=2100 \quad \mathrm{~N} \cdot \mathrm{s} / \mathrm{m}, \quad k=2.5 \times 10^{7} \mathrm{~N} / \mathrm{m}$, 

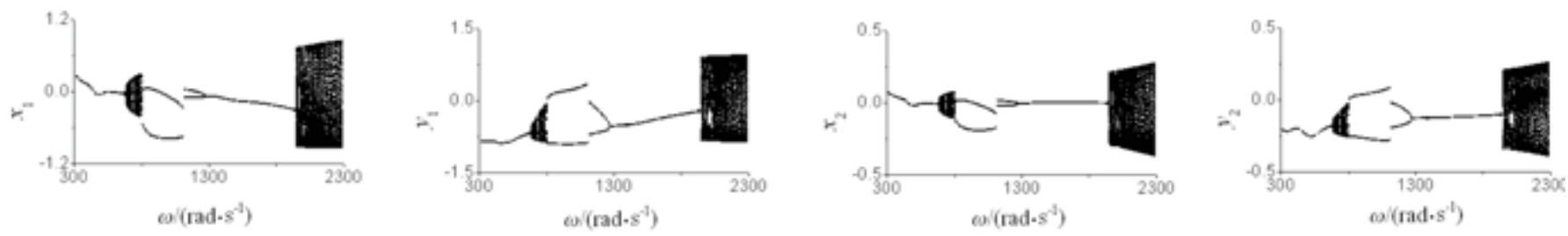

(a) Considering seal fluid force
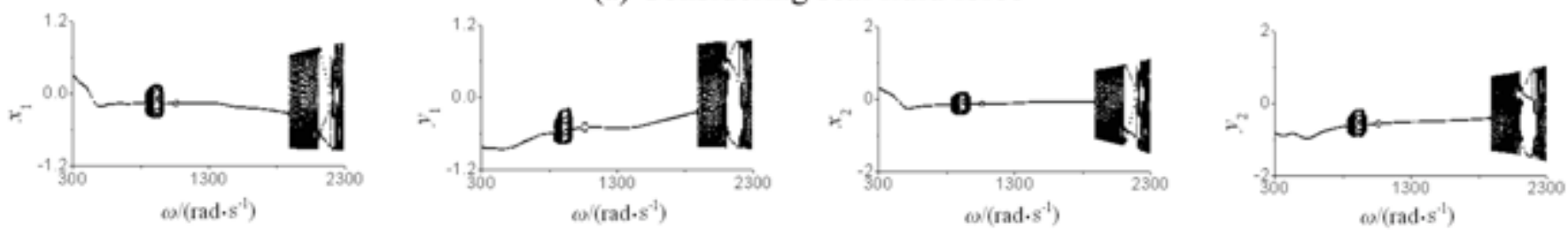

(b) Non seal fluid force

Fig. (2). The bifurcation diagrams of rotor response with $\omega$.

$k_{\mathrm{c}}=3.5 \times 10^{6} \mathrm{~N} / \mathrm{m}, e=0.04 \mathrm{~mm}$ and $\delta_{0}=0.1$. The physical and structural parameters of seal are: $n=2.5, b=0.45, \tau_{0}=0.4$ and $m_{0}=-0.25$. The imported loss coefficient of seal is $z=0.1$ and the axial velocity is $5 \mathrm{~m} / \mathrm{s}$. The first critical rotating speed of the system (with no fault) is $\omega_{0}=882.5 \mathrm{rad} / \mathrm{s}$. Fig. (2) shows the bifurcation diagrams of rotor-bearing-seal response with rotational speed. Fig. (2a) shows the bifurcation diagram of the seal fluid force and Fig. (2b) shows non-seal fluid force. It can be found by comparing Fig. (2a \& b) that there are distinct influences of nonlinear seal fluid force on the responses of the rubbing system. It can be seen from Fig. (2a) that along with the increase of the rotational speed, at about $\omega=680 \mathrm{rad} / \mathrm{s}$, the system loses stability of the periodic motion, and bifurcates from periodic-1 to quasi-periodic motion. The main motions in the region of supercritical rotational speed are periodic-1 and periodic-2 motions, and of ultra-supercritical rotational speed is quasi-periodic motion. From Fig. (2b), we can see that at about $\omega=810 \mathrm{rad} / \mathrm{s}$, the system loses stability of the periodic motion, and bifurcates from periodic-1 to quasiperiodic motion. The main motion in the region of supercritical rotational speed is periodic-1 motion, and of ultra-supercritical rotational speed is quasi-periodic and periodic- $n$ motion. However, the amplitude increases significantly compared with Fig. (2a). It illustrates that the seal fluid force increases the instability factor, which is not in favor of the stability of the system, but is in favor of the rotor response in ultra-supercritical rotational speed. Figs. (3, 4) show the responses of time-domain waveform, trajectory of journal centers, amplitude spectrum and Poincaré maps at different rotate speeds, which illustrate the periodic-1, periodic-2 and quasi-periodic motions.

\subsection{Influences of Rub-Impact Parameters on the Rotor Responses}

It can be seen from Figs. $(\mathbf{2 a} \& \mathbf{5})$ that when the nondimensional rubbing gap is $\delta_{0}=0.05$, the system loses stability of the periodic motion at about $\omega=730 \mathrm{rad} / \mathrm{s}$. When $\delta_{0}=0.10$, the system loses stability of the periodic motion at about $\omega=680 \mathrm{rad} / \mathrm{s}$. When $\delta_{0}=0.40$, the system loses stability of the periodic motion at about $\omega=560 \mathrm{rad} / \mathrm{s}$. Along with the increase of rubbing gap, the instability critical speed of the system decreases, and the quasi-periodic motion region increases, which is not in favor of the stability of the system. From Figs. (2a, 6) we can see that when the rubbing stiffness $k_{\mathrm{c}}=1.0 \times 10^{6} \mathrm{~N} / \mathrm{m}$, the system loses stability of the periodic motion at about $\omega=590 \mathrm{rad} / \mathrm{s}$. When $k_{\mathrm{c}}=3.5 \times 10^{6}$ $\mathrm{N} / \mathrm{m}$, the system loses stability of the periodic motion at about $\omega=680 \mathrm{rad} / \mathrm{s}$. When $k_{\mathrm{c}}=8.0 \times 10^{6} \mathrm{~N} / \mathrm{m}$, the system loses stability of the periodic motion at about $\omega=710 \mathrm{rad} / \mathrm{s}$. It illustrates that along with the increase of rubbing stiffness, the instability critical speed of the system increases, which is in favor of the stability of the system.

\section{CONCLUSION}

(1) The nonlinear dynamic model of rotor system with rub-impact fault is set up based on the coupling model of nonlinear oil-film force and nonlinear seal fluid force. The dynamic characteristics of the rotor system were studied with numerical simulation.

(2) The seal fluid force increases instability factor, which is not in favor of the stability of the system, but is in favor of the rotor response in ultra-supercritical rotational speed.

Along with the decrease of rubbing gap and increase of rubbing stiffness, the instability critical speed of 

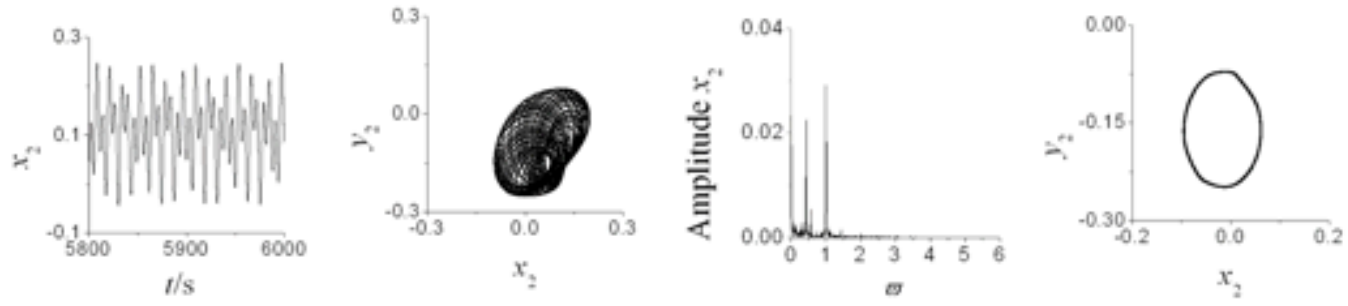

(a) $750 \mathrm{rad} / \mathrm{s}$
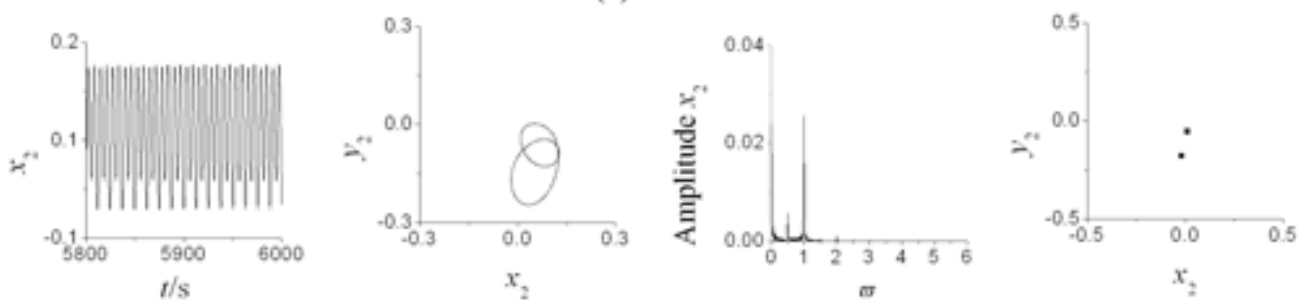

(b) $1200 \mathrm{rad} / \mathrm{s}$
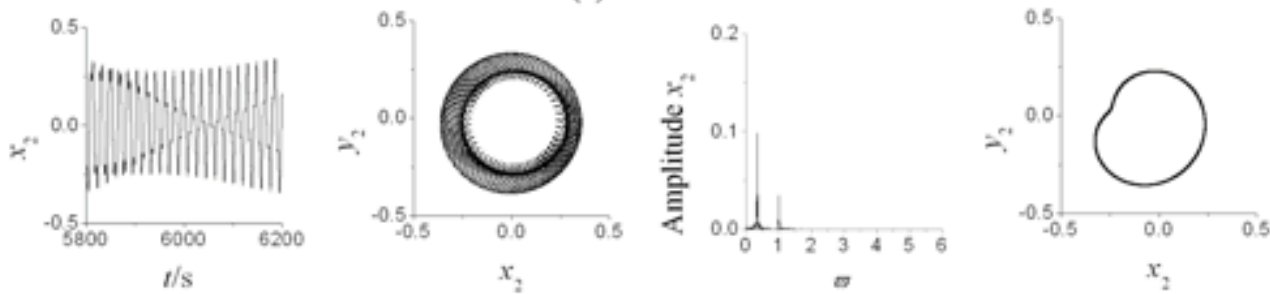

(c) $2100 \mathrm{rad} / \mathrm{s}$

Fig. (3). Responses of rotor system at different $\omega$ (Considering seal fluid force).
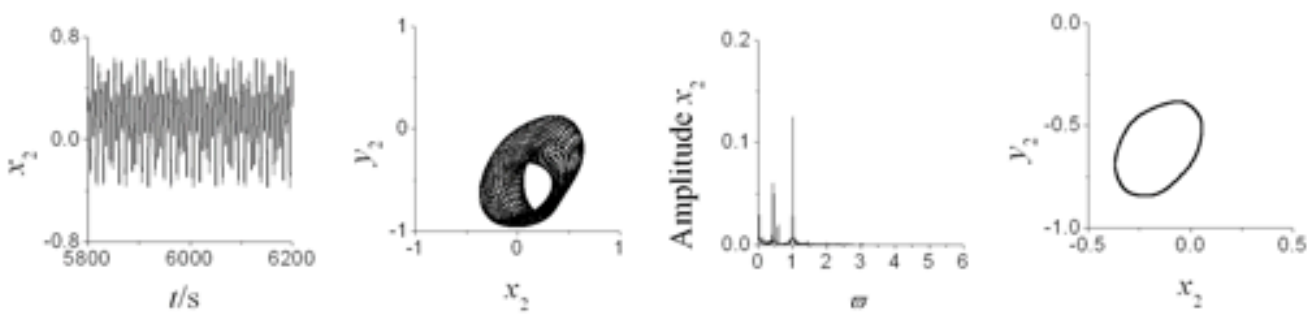

(a) $850 \mathrm{rad} / \mathrm{s}$
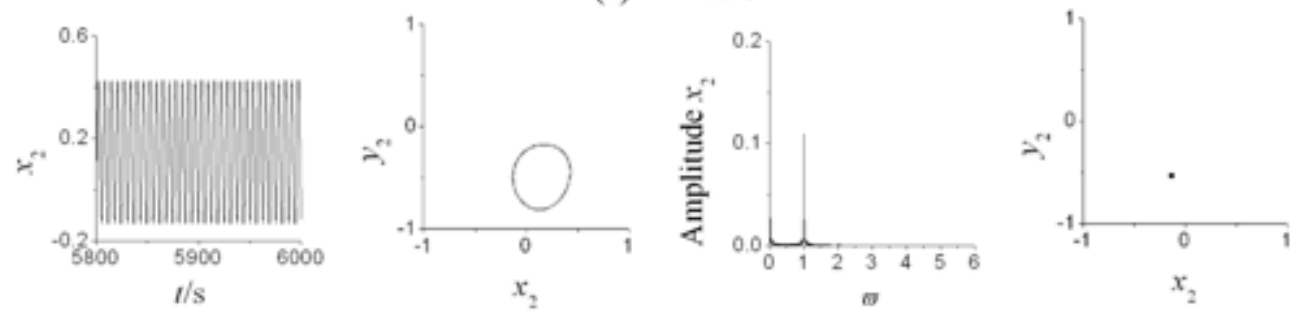

(b) $1200 \mathrm{rad} / \mathrm{s}$
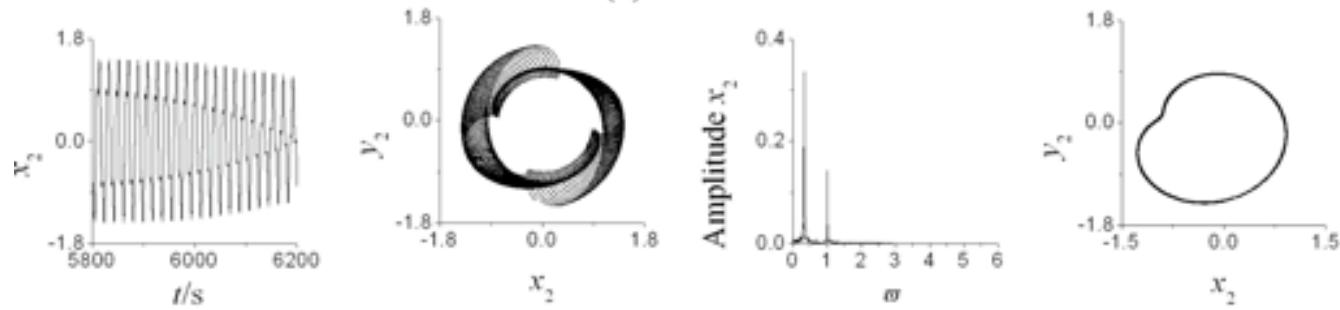

(c) $2100 \mathrm{rad} / \mathrm{s}$

Fig. (4). Responses of rotor system at different $\omega$ (Non-seal fluid force). 

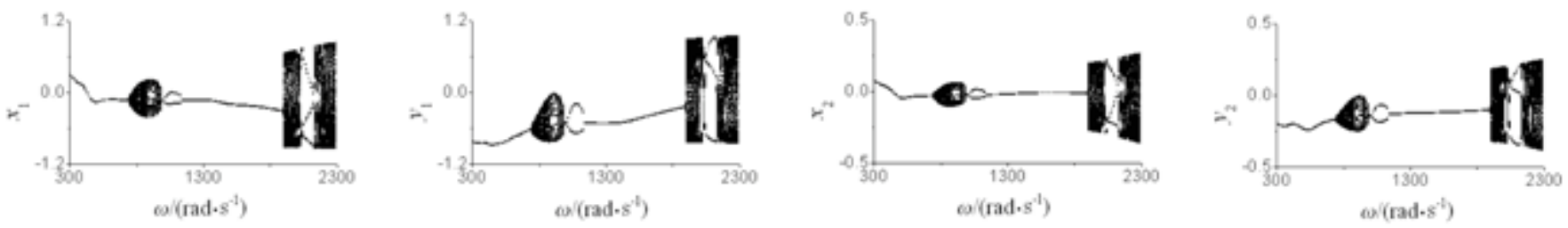

(a) $\delta_{0}=0.05$
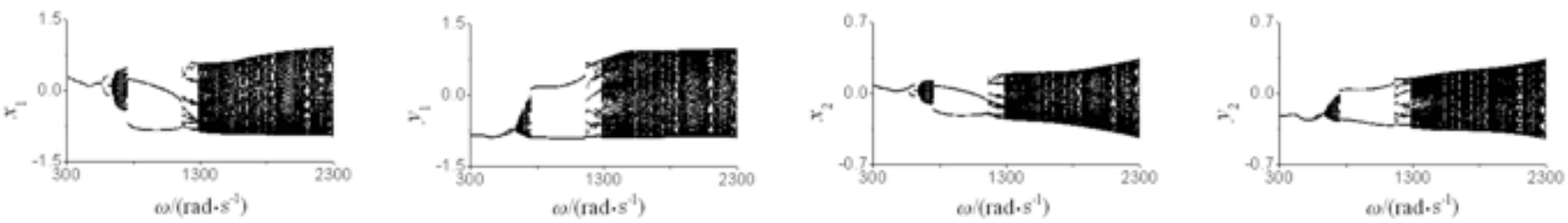

(b) $\delta_{0}=0.4$

Fig. (5). Bifurcation diagrams of rotor response with $\omega$ at different rubbing gaps.
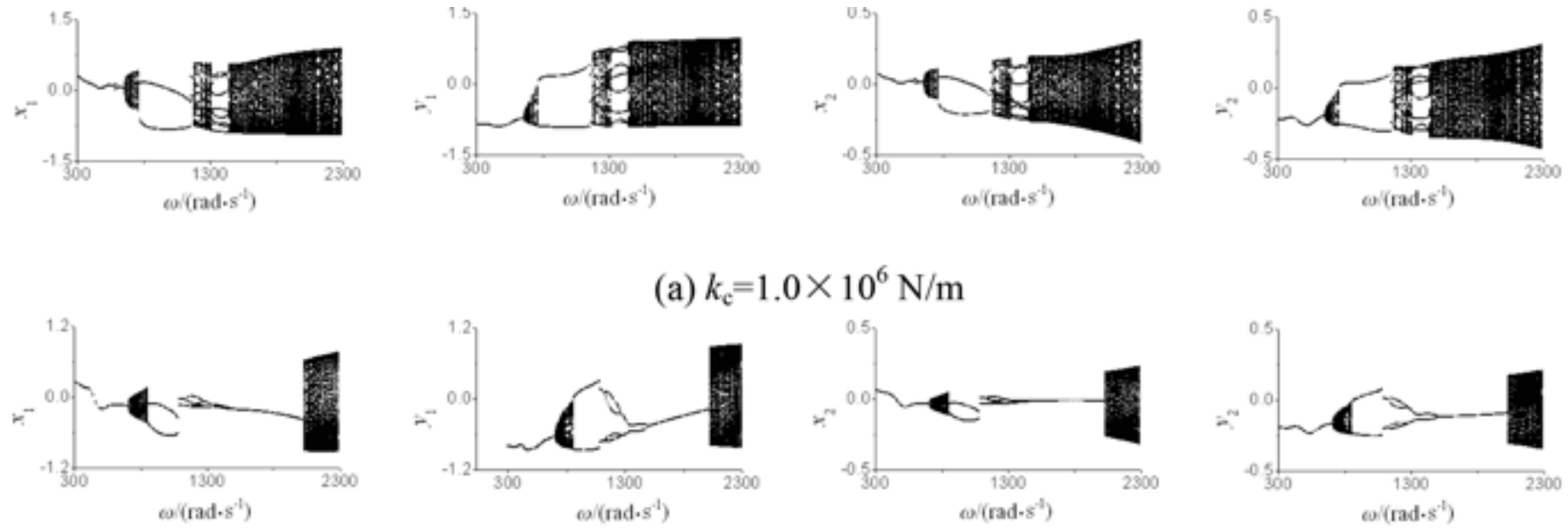

(b) $k_{\mathrm{c}}=8.0 \times 10^{6} \mathrm{~N} / \mathrm{m}$

Fig. (6). Bifurcation diagrams of rotor response with $\omega$ at different rubbing stiffness.

the system increases, and the quasi-periodic motion region decreases, which is in favor of the stability of the system.

\section{CONFLICT OF INTEREST}

The authors confirm that this article content has no conflict of interest.

\section{ACKNOWLEDGEMENTS}

This research is supported by the Fundamental Research Funds for the Central Universities (No. DC120101011), and by the Natural Science Foundation of Liaoning Province, China (No. 201202041).

\section{REFERENCES}

[1] F. Ehrich, "Nonlinear phenomena in dynamic response of rotors in anisotropic mounting systems", ASME Journal of Vibration and Acoustics, vol. 117, pp. 154-61, 1995.

[2] F. Chu, and Z. Zhang, "Periodic, quasi-periodic and chaotic vibrations of a rub-impact rotor system supported on oil film bearings", International Journal of Engineering Science, vol. 35, pp. 963-73, 1997.

[3] F. Chu, X. Tang, and Y. Tang, "Stability of a rub-impact rotor system", Journal of Tsinghua University (Sci \& Tech), vol. 40, pp. 119-23, 2000.

[4] Z. Sun, J. Xu, and P. Gong, "Study on dynamic characteristics of a rotor system with clearance", Journal of Vibration Engineering, vol. 13, pp. 474-80, 2000.

[5] Z. Wang, J. Wu, H. Yao, and B. Wen, "Rub-impact analysis of rotor system with slow-varying mass", Journal of Northeastern University(Natural Science), vol. 25, pp. 578-581, 2004

[6] C Z. Ren, H. Chen, H. Li, and B. Wen, "Numerical simulation and experimental analysis of rubbing fault in a dual-disc overhung rotor-bearing system", China Mechanical Engineering, vol. 17, pp. 1828-33, 2006.

[7] Y. Luo, S. Zhang, and B. Wen, "Study on nonlinear response and chaos of two-span rotor-bearing system with rub-impact fault", Mechanical Science and Technology for Aerospace Engineering, vol. 27, pp. 1271-4, 2008.

[8] C. Li, X. Li, H. Ma, and B. Wen, "The nonlinear dynamic behavior of a rotor-bearing system with rub-impact by a continuous model", Journal of Vibration Engineering, vol. 22, pp. 395-9, 2009. 
[9] Y. Yin, D. Yao, and S. Wang, "Coupled vibration analysis on nonlinear rotor-case-sealed rubbing system", Chinese Journal of Construction Machinery, vol. 6, pp. 269-75, 2008.

[10] Z. Yuan, Z. Li, S. Wang, X. Yue, and F. Chu, "Dynamic analysis in full degrees of freedom of rotor's axial rub-impact with consideration of nonlinear fluid-structure interaction forces", China Journal of Electrical Engineering, vol. 24, pp. 92-7, 2008.
[11] S. Zhang, Y. Luo, B. Wu, and B. Wen, "Dynamic behavior analysis of three-span rotor-bearing system with rub-impact fault", Advanced Materials Research, vol. 460, pp. 160-4, 2012.

[12] A. Muszynska and D. E. Bently, "Frequency swept rotating in put perturbation techniques and identification of the fluid models in rotor/bearing/seal systems and fluid handing machines", Journal of Sound and Vibration, vol. 143, pp. 103-24, 1990.

[13] W. Zhang, Theoretical basis of rotor dynamics: Science Press of China, 1990.

Received: September 10, 2014

Revised: November 5, 2014

Accepted: November 5, 2014

(C) Luo et al.; Licensee Bentham Open

This is an open access article licensed under the terms of the Creative Commons Attribution Non-Commercial License (http://creativecommons.org/licenses/ by-nc/4.0/) which permits unrestricted, non-commercial use, distribution and reproduction in any medium, provided the work is properly cited. 